\title{
RETENÇÃO DE PROTEÍNA E ENERGIA EM JUVENIS DE "BLACK BASS" Micropterus salmoides
}

\author{
José Eurico Possebon Cyrino ${ }^{1 *}$; Leandro Portz²; Ricardo Cavalcanti Martino ${ }^{3}$ \\ ${ }_{2}^{1}$ Depto. de Produção Animal - USP/ESALQ, C.P. 9 - CEP: 13418-900 - Piracicaba, SP. \\ ${ }_{3}^{2}$ Pós-Graduando do Depto de Produção Animal - USP/ESALQ. \\ ${ }^{3}$ Unidade de Tecnologia de Pescado. Fundação Instituto de Pesca do Estado do Rio de Janeiro/UFRJ - Ilha do \\ Fundão - Instituto de Biologia (CCS), Sala Ao.85 - CEP: 21944-970 - Rio de Janeiro, RJ. \\ *Autor correspondente<jepcyrin@carpa.ciagri.usp.br>
}

\begin{abstract}
RESUMO: O objetivo deste trabalho foi avaliar alterações nas formas de reserva de energia na carcaça de juvenis de "black bass" (14,46 $\pm 0,81 \mathrm{~g}$ de peso vivo). Peixes condicionados a aceitar alimento artificial foram estocados em 90 gaiolas de volume $60 \mathrm{~L}$ alojadas em caixas de $1.000 \mathrm{~L}$ em laboratório com condições ambientais controladas, e alimentados por 64 dias com rações extrusadas com níveis de proteína variando entre 34 e $54 \%$ (incrementos de $4 \%$ ) e teores de energia digestível variando de 3.600 a $4.100 \mathrm{kcal} \mathrm{kg}^{-1}$ de alimento (incrementos de $125 \mathrm{kcal} \mathrm{kg}^{-1}$ ). Foram analisados as variáveis de ganho de peso, consumo alimentar diário, relação hepato-somática, relação víscero-somática, deposição protéica e energética, glicogênio tecidual hepático e lipídio visceral. Não houve interação $(P>0,05)$ entre níveis de proteína e energia para os parâmetros avaliados. Os níveis de proteína e energia digestível dietética que garantiram melhor desempenho foram $42 \%$ e 3.850 $\mathrm{kcal} \mathrm{kg}^{-1}$, respectivamente. Dietas com teores médios de $42 \%$ de proteína bruta, induziram um alto acúmulo de glicogênio hepático $(P<0,0442)$, assim como aumento da relação hepato-somática $(P<0,0001)$, mostrando alta eficiência no acúmulo de energia prontamente utilizável bem como melhor capacidade de retenção dos nutrientes, quando os níveis de carboidratos foram inferiores a 30\% na ração. O aumento dos níveis de energia das dietas, através da inclusão de óleo nas rações, induziu aumentos significativos no acúmulo total de lipídios na carcaça quando as médias eram agrupadas por níveis de energia, e induziu acúmulo de lipídios nas vísceras para os agrupamentos de médias tanto por teor de proteína $(P<0,0001)$ como de energia dietética $(\mathrm{P}<0,0021)$.

Palavras-chave: Micropterus salmoides, proteína, energia, glicogênio, lipídio
\end{abstract}

\section{PROTEIN AND ENERGY RETENTION BY JUVENILE LARGEMOUTH BASS Micropterus salmoides}

\begin{abstract}
To determine dietary protein and energy retention of juvenile largemouth bass one thousand, three hundred and fifty feed-conditioned fish (average weight $14.46 \pm 0.81 \mathrm{~g}$ ) were stocked in $60-\mathrm{L}$ cages set up in $1,000 \mathrm{~L}$ containers, and fed for 64 days with a dry, extruded feed containing varying levels of crude protein $\mathrm{CP}(34,38,42,46,50$ and $54 \%)$ and energy $\left(3,600\right.$ to $4,100 \mathrm{kcal} \mathrm{kg}^{-1}$ feed, with increases of $\left.125 \mathrm{kcal} \mathrm{kg}^{-1}\right)$. The trial was set up in a totally randomized $6 \times 5$ factorial design $(n=3)$. Data on weight gain, daily feed consumption, hepatosomatic index, viscerosomatic index, nutrient protein, energy retention, liver glycogen and visceral fat were evaluated. There were no interaction effects $(P>0.05)$ between feed energy and protein levels in respect to all evaluated parameters. Best performance was attained with levels of $42 \% \mathrm{CP}$ and $3,850 \mathrm{kcal} \mathrm{kg}^{-1}$ in the diets, a condition which resulted in higher levels of liver glycogen $(P<0.0442)$ and higher hepatosomatic indexes $(P<0.0001)$ usually when diets presented less than $30 \%$ starch. Higher levels of dietary lipid induced significant increases in whole body lipids considering dietary energy $(P<0.0001)$, and this also induced higher deposition of visceral fat for pooled means of dietary protein $(P<0.0001)$ and energy $(P<0.0021)$ contents. These results will help understanding the nutritional energetics of carnivorous fish, increasing the feasibility of their intensive production.

Key words: Micropterus salmoides, protein, energy, glycogen, lipid
\end{abstract}

\section{INTRODUÇÃO}

A proteína e os lipídios são nutrientes importantes na mobilização e formação de tecido corporal, sendo os principais responsáveis pelo crescimento e ganho de peso nos peixes carnívoros. A utilização da proteína e os níveis de inclusão em rações para as várias espécies carnívoras tem sido foco de várias pesquisas na área de nutrição de peixes (Anderson et al., 1981; Brecka et al. 1996; Murai, 1992; Tidwell et al., 1996).
Altos níveis de proteína geralmente causam um desbalanço na relação energia:proteína nas dietas, fazendo com que os peixes supram suas necessidades em energia a partir da elevação do consumo de alimento, piorando a conversão alimentar e reduzindo o ritmo de ganho de peso, com sérios prejuízos aos resultados econômicos das criações. Deste modo, pesquisas sobre as exigências em proteína, energia e adequação da relação energia:proteína em rações para peixes são oportunas e necessárias (Hanley, 1991). 
Segundo Shearer (1994), em peixes juvenis o crescimento da carcaça é maior que o crescimento das outras partes do corpo, onde os órgãos internos, com exceção do lipídio visceral, tendem a aumentar de peso em proporções pequenas. Este mesmo autor cita que 0 tamanho relativo dos tecidos e órgãos, sob condições adequadas de nutrição, são dependentes apenas do tamanho do peixe e ciclo de vida. Entretanto, em geral são encontradas diferenças marcantes em tamanho e peso do fígado de peixes alimentados com diferentes dietas.

O crescimento e a composição química corporal dos peixes podem ser influenciados pela manipulação dos diferentes alimentos e rações a eles fornecidos. Poucos são os autores que descrevem a composição dos depósitos energéticos de peixes alimentados com diferentes rações, e poucas são as informações sobre o efeito da utilização de diferentes alimentos na composição da reserva energética de diferentes tecidos (Jobling et al., 1998).

O glicogênio é uma das muitas formas de armazenamento da energia consumida como alimento pelo peixe. O glicogênio é encontrado em grande quantidade nos tecidos do fígado e músculo dos peixes. Embora o tecido muscular de peixes carnívoros, como a truta arcoíris, possa concentrar cerca de $6 \%$ a mais glicogênio que o fígado, as quantidades totais de glicogênio muscular ou hepático podem ser consideradas iguais (Steffens, 1989).

Como consequência de uma intensa atividade física, as reservas de glicogênio no músculo e fígado dos peixes podem diminuir em poucos minutos, sendo restabelecidas somente 24 horas após terem sido consumidas. Nagai \& Ikeda (1971) mostraram que períodos de restrição alimentar superiores a 164 dias não resultam em uma queda significativa na reserva de glicogênio muscular da carpa comum, embora estes peixes tenham mostrado uma redução de $75 \%$ na reserva de glicogênio tecidual hepático após 100 dias de restrição alimentar. Isto mostra que estes peixes iniciam a utilização das reservas de glicogênio do corpo a partir do glicogênio tecidual hepático.

O glicogênio hepático é considerado um estoque emergencial de energia prontamente utilizável nos primeiros momentos de situações críticas de estresse (Christiansen \& Klungsoyr, 1987). Os polissacarídeos são encontrados em todas as células dos animais e mais abundantemente no fígado, alcançando normalmente 7\% do peso seco do tecido (Stryer, 1971).

O ciclo do glicogênio hepático no catabolismo mostra que esta forma de reserva orgânica é muito mais importante como suprimento de intermediários metabólicos para processos biosintéticos, que fonte de energia (Christiansen \& Klungsoyr, 1987). O glicogênio é um nutriente muito utilizado em adaptações bioquímicas em várias situações de estresse ambiental. Variações do pH, dos níveis de oxigênio dissolvido na água, da salinidade, e períodos de grande esforço físico e mudanças de dietas podem resultar tanto em aumento como em diminuição do estoque de glicogênio (Moraes et al., 1996; Soengas et al., 1995).
Diversos estudos conduzidos com diferentes espécies de peixes nas mais diversas condições ambientais têm utilizado a avaliação da relação hepatosomática e do peso da gordura visceral como forma de quantificar o estoque energético (i.e. lipídeos e glicogênio) em peixes (Bidinoto et al., 1997; Heidinger \& Crawford, 1977; Nematipour et al., 1992a, b). Brown et al. (1992) testaram níveis de proteína dietética variando de 25 a 55\%, com incremento de 5\%, na alimentação de juvenis de "sunshine bass" e utilizaram a relação hepato-somática (RHS) como uma medida relativa de estoque energético. Os autores observaram que os valores da relação hepatosomática encontrados eram inversamente proporcionais aos níveis de proteína e diretamente proporcionais aos níveis de carboidratos digestíveis dietéticos, o que mostra que quanto menor o nível de proteína dietética, maior a utilização de carboidratos e a deposição de glicogênio no fígado. Resultados semelhantes também foram mostrados por Millikin (1982) para o "striped bass".

A relação entre a quantidade de gordura visceral e o peso do corpo também comporta-se de forma similar à RHS, ou seja, apresenta um declínio diretamente proporcional ao aumento da quantidade de proteína dietética (Brown et al., 1992). As reservas energéticas dos peixes são geralmente representadas por um acúmulo de gordura visceral. Tais reservas em peixes não sexualmente maduros podem acontecer como acúmulo de gordura muscular, e são necessárias para crescimento e como reserva energética para o período de falta de alimento ou anorexia de inverno (Wicker \& Johnson, 1987). O aumento da relação gordura visceral:peso do corpo é diretamente proporcional ao aumento da RHS e reflete a proporcionalidade entre ambas as formas de acúmulo de energia.

O objetivo deste estudo foi avaliar o efeito de diferentes níveis de proteína e energia dietéticos nas formas e quantidades das reservas de energia da carcaça de juvenis de black bass, relacionando estas alterações às exigências em proteína e energia dietéticas, bem como à relação energia:proteína dietética ideal para a espécie.

\section{MATERIAL E MÉTODOS}

O experimento foi conduzido no Laboratório de Nutrição de Peixes do Departamento de Produção Animal da Escola Superior de Agricultura "Luiz de Queiroz", da Universidade de São Paulo, em Piracicaba, SP. O laboratório é equipado com 32 tanques de polipropileno com capacidade de $1.000 \mathrm{~L}$. Cada tanque aloja 3 gaiolas de volume igual a $60 \mathrm{~L}$, confeccionadas em tela de policloreto de vinila atóxico com abertura de malha $5 \mathrm{~mm}$, e possui sistema fechado de recirculação da água (uma troca completa a cada 3 horas) através de um filtro biológico, aeração forçada por difusores, com sistema de oxigenação de emergência através de borbulhamento de oxigênio gasoso, e temperatura controlada por bomba de troca de calor, mantida em $24 \pm 1^{\circ} \mathrm{C}$. 
A iluminação do ambiente era feita por 8 lâmpadas de halogênio de 370 watts, controladas por temporizador, mantendo um fotoperíodo de 14 horas de luz e 10 de escuro, segundo recomendações de Heinen (1998). Os parâmetros de qualidade da água: temperatura, $\mathrm{pH}$, oxigênio dissolvido, amônia e nitrito eram monitorados diariamente por equipamentos eletrônicos, no período da manhã e da tarde.

Foram formuladas rações com níveis crescentes de proteína: $34,38,42,46,50,54 \%$ e com cinco níveis de energia digestível: $3600,3725,3850,3975,4100 \mathrm{kcal}$ $\mathrm{kg}^{-1}$ para cada nível de proteína, através de um aplicativo de programação linear para formulação de rações de custo mínimo. A farinha de peixe chilena foi utilizada como ingrediente protéico padrão (Contreras G., 1999; Pezzato $1995,1997)$ em concentração nunca excedendo $46,35 \%$ da ração. Os valores de digestibilidade de energia dos ingredientes foram calculados com base nos dados obtidos por Sullivan \& Reigh (1995) e Gallagher (1997) para o "striped bass" híbrido, e do NRC (1993) para a truta arcoíris. O nível de amido das rações foi fixado entre 15 e 30\% a fim de permitir expansão do material durante 0 processamento (TABELA 1). As rações foram processadas na forma de grânulos extrusados de diâmetro igual a 3,5 $\pm 0,5 \mathrm{~mm}$ em uma extrusora Imbramaq MX-300 com capacidade para $300 \mathrm{~kg} \mathrm{~h}^{-1}$ (Hui-Meng, 1989; Kearns 1989, 1999).

Foram utilizados 1350 black bass já condicionados a aceitar o alimento artificial (Lovshin \& Rushing, 1989), com 14,46 $\pm 0,81 \mathrm{~g}$ de peso vivo, criados com ração comercial seca, flutuante, para peixes carnívoros. Os peixes foram alimentados diariamente em duas refeições (7h00 m e $17 \mathrm{~h} 00 \mathrm{~m}$ ) por um período de 64 dias. As taxas de alimentação foram calculadas e expressas pela relação percentual entre o consumo de alimento diário e a biomassa de cada parcela. Para montagem do experimento, os peixes foram submetidos a jejum por 24 horas, anestesiados em benzocaína 1\%, pesados em balança semi-analítica com precisão de $0,001 \mathrm{~g}$ e separados em lotes de 15 peixes, que foram aleatoriamente distribuídos nas parcelas, em um delineamento experimental inteiramente casualizado em esquema fatorial $6 \times 5$, com três repetições por tratamento. Um lote de 15 peixes foi sacrificado por superdosagem de

TABELA 1 - Ingredientes e níveis de nutrientes determinados nas rações experimentais.

\begin{tabular}{|c|c|c|c|c|c|c|}
\hline \multirow[b]{2}{*}{ Ingredientes } & \multicolumn{6}{|c|}{ Nível protéico da dieta (\%) } \\
\hline & 34 & 38 & 42 & 46 & 50 & 54 \\
\hline & \multicolumn{6}{|c|}{ nateria seca } \\
\hline Farinha de peixe chilena ${ }^{a}$ & 45,35 & 45,35 & 45,35 & 45,35 & 42,35 & 22 \\
\hline Farelo de Soja & - & 6 & 17 & 9 & 4 & - \\
\hline Glutenose $(60 \%)$ & - & - & 1 & 15 & 33 & 46,87 \\
\hline Milho & 34 & - & - & - & - & - \\
\hline Farelo de Trigo & 4 & - & - & - & - & - \\
\hline Amido de milho & - & - & - & 2 & 9 & 2 \\
\hline Farinha de trigo & 8 & 40 & 28 & 23 & 6 & 13 \\
\hline L-Lisina $(80 \%)$ & - & - & - & - & - & 8,48 \\
\hline Óleo de Soja & 8 & 8 & 8 & 5 & 5 & 7 \\
\hline Mistura mineral e vitamínicab & 0,6 & 0,6 & 0,6 & 0,6 & 0,6 & 0,6 \\
\hline Vitamina C (Stay-C 42\%) ${ }^{c}$ & 0,05 & 0,05 & 0,05 & 0,05 & 0,05 & 0,05 \\
\hline \multicolumn{7}{|l|}{ Níveis de nutrientes } \\
\hline Proteína bruta (\%) & 34,02 & 37,17 & 41,76 & 45,53 & 50,72 & 53,29 \\
\hline Lipídio bruto (\%) & 13,42 & 12,80 & 12,23 & 10,00 & 10,00 & 10,00 \\
\hline Amido (\%) & 30,00 & 27,83 & 20,00 & 20,00 & 18,00 & 17,10 \\
\hline Fibra bruta (\%) & 1,72 & 1,41 & 2,10 & 1,76 & 1,50 & 1,43 \\
\hline ENN (\%) & 32,72 & 30,66 & 24,63 & 22,68 & 21,40 & 21,98 \\
\hline Energia digestível $\left(\mathrm{kcal} \mathrm{kg}^{-1}\right)^{d}$ & 3850 & 3850 & 3850 & 3850 & 3850 & 3850 \\
\hline Relação energia/proteína (kcal g-1) & 11,32 & 10,13 & 9,17 & 8,37 & 7,70 & 7,13 \\
\hline
\end{tabular}

aComposição (g $100 \mathrm{~g}^{-1}$ de peso seco): proteína bruta, 64,06; lipídio bruto, 11,59.

bSuplementação/kg de ração: $40 \mathrm{mg}$ de $\mathrm{Mn} ; 100 \mathrm{mg}$ de Fe; $100 \mathrm{mg}$ de Zn; $10 \mathrm{mg}$ de Cu; $1 \mathrm{mg}$ de Co; $1,5 \mathrm{mg}$ de I; 36.000 UI de vitamina A; $9 \mathrm{mg}$ de $\mathrm{B}_{6} ; 4.500 \mathrm{Ul}$ de $\mathrm{D}_{3} ; 150 \mathrm{UI}$ de vitamina $\mathrm{E} ; 90 \mathrm{mcg}$ de $\mathrm{B}_{12} ; 6 \mathrm{mg}$ de $\mathrm{B}_{1} ; 18 \mathrm{mg}$ de $\mathrm{B}_{2} ; 4,5 \mathrm{mg}$ de $\mathrm{K}_{3} ; 9 \mathrm{mg}$ de Ácido fólico; $0.6 \mathrm{mg}$ de Biotina; $0,45 \mathrm{mg}$ de Selênio; $30 \mathrm{mg}$ de Ácido pantotênico; $90 \mathrm{mg}$ de Ácido nicotínico

'Suplementação/kg de ração: $346 \mathrm{mg}$

dValores calculados com base nos coeficientes de digestibilidade da energia para "striped bass", apresentados por Sullivan et al., (1995) e Gallagher (1997). 
benzocaína, enxaguado, triturado, congelado de imediato em recipiente imerso em nitrogênio líquido, e armazenado em super congelador $\left(-80^{\circ} \mathrm{C}\right)$, para determinação de composição centesimal inicial da carcaça (matéria original).

Para determinação do glicogênio hepático, três peixes dos estoques inicial e final mantidos em jejum foram anestesiados e dissecados para retirada do fígado. Os fígados coletados foram colocados em tubos de Ependorff $(1,5 \mathrm{~mL})$, congelados imediatamente por imersão em nitrogênio líquido e armazenados em super-congelador $\left(-80^{\circ} \mathrm{C}\right)$, para posterior determinação da quantidade de glicogênio tecidual. Para a retirada das vísceras, 3 peixes foram anestesiados e suas vísceras foram retiradas (exceto o coração) juntamente com a gordura acumulada na cavidade abdominal. O material visceral coletado foi colocado separadamente em tubos de Falcon de $45 \mathrm{~mL}$, congelado imediatamente por imersão em nitrogênio líquido e armazenado em super congelador, para posterior determinação da quantidade de lipídio total.

No final do experimento, após jejum de 24 horas, os peixes foram anestesiados e foi obtido o peso final de cada parcela. Uma amostra de 6 peixes foi aleatoriamente coletada de cada parcela. Estes peixes foram sacrificados e armazenados como descrito para posterior análise da composição centesimal da carcaça (matéria original). Foram registrados o peso vivo e do fígado e/ou víscera dos três peixes de cada repetição, para cálculo das relações hepato e lipo-somáticas.

Com exceção da fração lipídio bruto, determinada pelo método de extração clorofórmio-metanol para 5,00 \pm $0,0001 \mathrm{~g}$ de amostra úmida (Folch et al., 1957), e da fração glicogênio tecidual, analisado através de "kit" de determinação Trinder (Sigma) em placas de ELISA, com leitura feita a $505 \mathrm{~nm}$ em espectrofotômetro MRXTC Plus (Dynex Technologies), segundo metodologia descrita por Moon et al. (1989), o procedimento das análises seguiu metodologia padrão da "Official Methods of Analysis of the Association of Official Analytical Chemists" (AOAC, 1985), sob padronização do Compêndio Brasileiro de Nutrição Animal (MARA, 1998). As amostras foram liofilizadas para a determinação da energia, que foi feita em uma fração de 1,00 $\pm 0,0001$ $\mathrm{g}$ através de bomba calorimétrica PARR 1261.

Os resultados de desempenho e composição centesimal da carcaça foram submetidos à análise de variância e ao teste de comparação de médias de Tukey, usando-se o pacote estatístico do aplicativo SAS (1985), (TABELA 2). Os parâmetros de desempenho avaliados neste experimento seguem descrições e recomendações de Erfanullah \& Jafri (1999), Hung et al. (1989), Moore et al. (1988), Steffens (1989) e Takeuchi (1988). Foram avaliados os seguintes parâmetros:

- Consumo alimentar diário: CAD (\%) $C A D=100 \times\left[A_{t} \div\left(P C_{m} \times P E x\right)\right]$, onde: $A C_{t}=$ alimento consumido total; $\mathrm{PC}_{\mathrm{m}}=$ peso corporal médio; PEx = período experimental (dias)

- Ganho de peso relativo: GDP $(\%)$ $G P_{r}=100 \times\left(P_{f}-P_{i}\right) \div P_{i}$
- Conversão alimentar: CA $\mathrm{CA}=\mathrm{P}_{\mathrm{al}} \div \mathrm{GDP}_{\mathrm{a}}$, onde: $\mathrm{P}_{\mathrm{al}}=$ peso do alimento fornecido

- Coeficiente de Retenção Protéica: CRP (\%) $\mathrm{CRP}=100 \times\left[\left(\mathrm{P}_{\mathrm{f}} \times \mathrm{PBC}_{\mathrm{f}}\right)-\left(\mathrm{P}_{\mathrm{i}} \times \mathrm{PBC}_{\mathrm{j}}\right)\right] \div \mathrm{AC}_{\mathrm{t}} \times$ $\mathrm{PB}_{c}$, onde: $\mathrm{PBC}_{\mathrm{f}}=$ proteína corporal final; $\mathrm{PBC}_{i}=$ proteína corporal inicial

- Coeficiente de Retenção Energética: CRE (\%) CRE $=100 \times\left[\left(P_{f} \times E B_{f}\right)-\left(P_{i} \times E_{i} C_{i}\right)\right] \div A_{t} \times$ $E D_{c}$, onde: $E_{B C}=$ energia bruta corporal final; $\mathrm{EBC}_{\mathrm{i}}=$ energia bruta corporal inicial; $\mathrm{ED}_{\mathrm{c}}=$ energia digestível da dieta

- Relação hepato-somática: RHS (\%) RHS $=100 \times\left(P_{\text {th }} \div \mathrm{PC}_{\mathrm{m}}\right)$, onde $\mathrm{P}_{\text {th }}=$ peso do tecido hepático

- Relação víscero-somática: RVS (\%) RVS $=100 \times\left(P_{v} \div P_{m}\right)$, onde: $P_{v}=$ peso das vísceras

${ }^{1}$ Vísceras = fígado, gônadas, trato gastrointestinal vazio e gordura mesentérica .

\section{RESULTADOS E DISCUSSÃO}

Os parâmetros de qualidade da água avaliados permaneceram normais e dentro das condições ótimas para o crescimento da espécie em todos os tratamentos. Os valores médios observados para os parâmetros monitorados foram: $\mathrm{pH} 7,5 \pm 0,3$; oxigênio dissolvido 5,3 $\pm 1,4 \mathrm{mg} \mathrm{L}^{-1}$; temperatura $25,3 \pm 1,6^{\circ} \mathrm{C}$; amônia total 0,3 $\pm 0,1 \mathrm{mg} \mathrm{L}^{-1}$; nitrito $0,27 \pm 0,2 \mathrm{mg} \mathrm{L}^{-1}$. Apenas sete peixes morreram nas diferentes parcelas, o que representa uma taxa de sobrevivência total de $99,48 \%$.

Os resultados obtidos pelos autores em estudo anterior mostraram que as exigências nutricionais mínimas de juvenis de black bass são $43,59 \%$ de proteína e 3.871 $\mathrm{kcal} \mathrm{kg}^{-1} \mathrm{ED}$ de alimento. Aqueles resultados permitiram inferir ainda que os limites da relação energia:proteína para nutrição do black bass estão entre 7,78 e $8,83 \mathrm{kcal} \mathrm{g}^{-1}$, condições em que a conversão alimentar varia de 0,96 a 1,10 , respectivamente. Para estes níveis de nutrientes, foram obtidos os melhores valores de CRP $(33,14 \%)$ e CRE $(111,61 \%)$ na carcaça. Estes dados podem ser observados na TABELA 1, e são corroborados pelas observações de Anderson et al. (1981).

Não foi encontrada interação $(P>0,05)$ entre os níveis de proteína e energia para os parâmetros de retenção de nutrientes avaliados. Os valores da RHS diferiram entre os tratamentos $(P<0,0001)$. Foram calculados valores mais altos de RHS para os níveis de $38,42,46 \%$ de PB na dieta. Nestas dietas, os níveis de carboidrato (ENN) variaram de 20 a $28 \%$ (TABELA 1). Os diferentes níveis de energia da dieta não influenciaram os valores de RHS e glicogênio total do fígado (TABELA 3).

Estudos com peixes carnívoros como a truta arcoíris (Hilton \& Atkinson, 1982; Refstie \& Austreng, 1981), "striped bass" (Millikin, 1982), bagre do canal (Garling \& Wilson, 1977) e "European sea bass" (Dias et al., 1998), demonstraram que há um aumento RHS proporcional ao 
aumento dos níveis de carboidratos digestíveis nas dieta. Lee \& Putman (1973) também relacionaram o aumento da RHS ao aumento do teor de proteína em dietas para o bagre do canal.
Os níveis mais altos de glicogênio tecidual hepático (GTH), os valores mais altos de RHS, e os níveis mais baixos de depósito lipídico, tanto na carcaça como nas vísceras, foram observados nos peixes alimentados

TABELA 2 - Composição centesimal da carcaça e desempenho dos peixes.

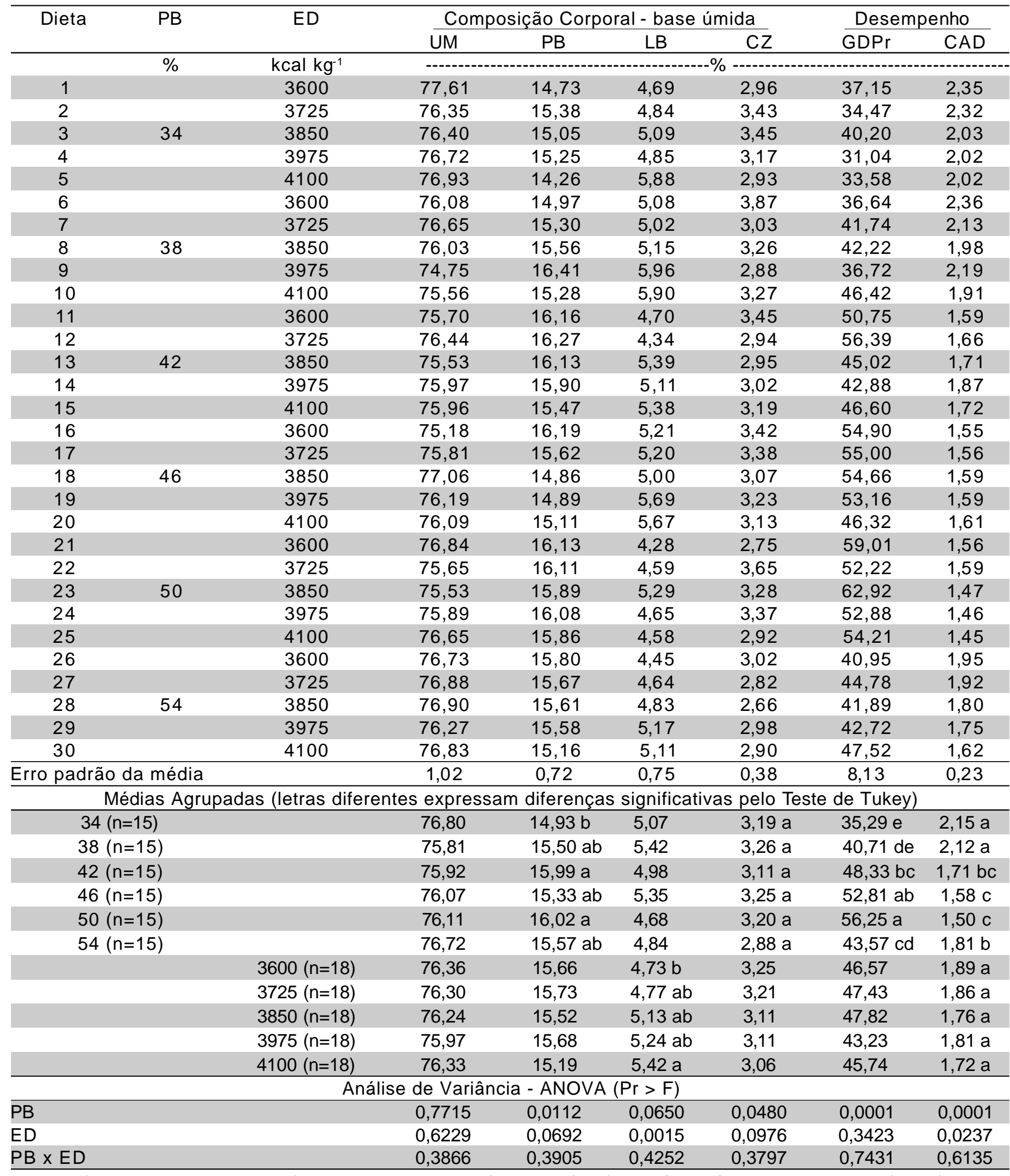

$\mathrm{PB}=$ Proteína bruta; $\mathrm{ED}=$ Energia digestível; $\mathrm{UM}=$ umidade; $\mathrm{LB}=$ Lipídeo bruto; $\mathrm{CZ}=$ Cinzas; $\mathrm{GDPr}=$ Ganho de peso relativo; $\mathrm{CAD}=\mathrm{Conversão}$ alimentar diária. 
com a dieta contendo $42 \%$ de PB (Figura 1). Isto mostra que rações contendo níveis de proteína próximos a $42 \%$ condicionam um maior acúmulo de reservas energéticas prontamente utilizáveis na forma de glicogênio. Pode-se então inferir que o "black bass" pode utilizar eficientemente dietas artificiais desde que os níveis de carboidratos sejam inferiores a $30 \%$ e as rações sejam adequadamente processadas (extrusadas). Resultados semelhantes foram

TABELA 3 - Relações somáticas e deposição de nutrientes da carcaça.

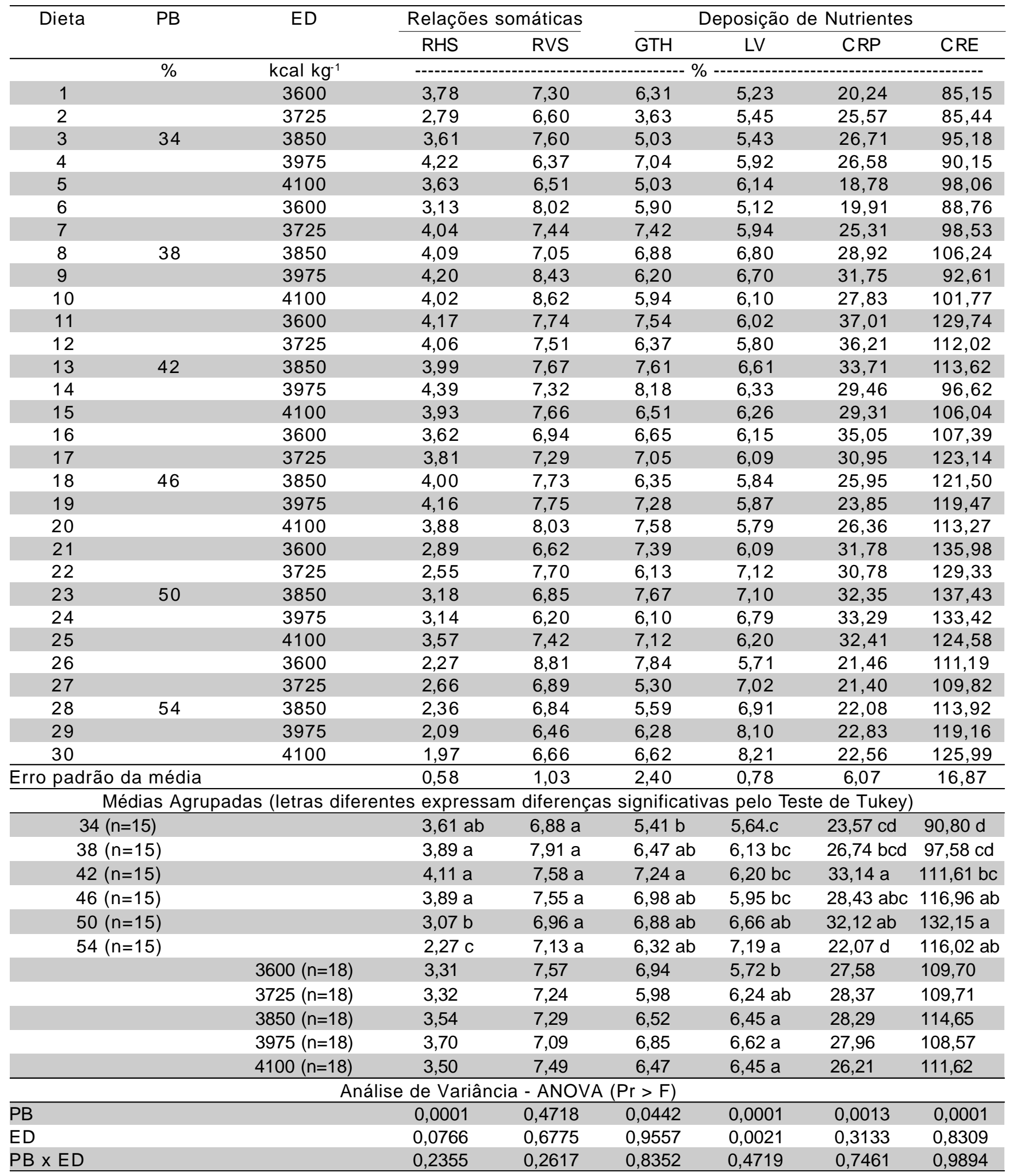

RHS= Relação hepato-somática; RVS= Relação víscero-somática; GTH= Glicogênio tecidual hepático; LV= Lipídeo visceral; CRP= Coeficiente de retenção protéica; $\mathrm{CRE}=$ Coeficiente de retenção energética. 
relatados por Pérez et al. (1997) para o "European sea bass" que, alimentado com dietas extrusadas com diferentes níveis protéicos e níveis de lipídios variando entre 12 e $14 \%$, e níveis de carboidratos de até $30 \%$, não apresentaram queda de desempenho.

Os valores da RVS não diferiram $(P>0,05)$ entre os tratamentos (Figura 2). Isto pode ser explicado pela variação individual observada para o peso, tamanho e volume das vísceras dos peixes, independentemente do tratamento a que foram submetidos. A quantidade de lipídio visceral inicial foi de $5,41 \%$. Ao contrário dos resultados observados em relação ao acúmulo total de lipídio no corpo, esta variável foi afetada tanto pela variação dos níveis de proteína $(P<0,0001)$ quanto de energia $(P<0,0021)$ na dieta. Os maiores depósitos de gordura visceral ocorreram nos peixes que receberam rações com 50 e $54 \%$ de PB e $3.850,3.975$ e $4.100 \mathrm{kcal} \mathrm{kg}^{-1}$ de ED. Isto permite inferir que níveis mais elevados de proteína e energia digestível em dietas para "black bass", induz um armazenamento do excesso de energia não prontamente utilizável na forma de lipídios viscerais. Esta inferência pode ser corroborada pelo fato de os valores de glicogênio acumulado e peso do fígado terem sido inversamente proporcionais aos níveis de lipídio visceral.

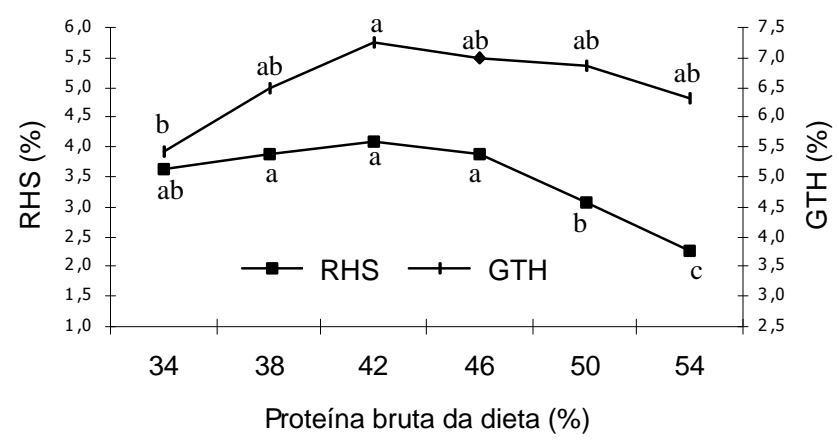

Figura 1 - Relação hepato-somática (RHS) e níveis de glicogênio do tecido hepático (GTH) (letras diferentes representam diferenças pelo Teste de Tukey $\mathrm{P}<0,05)$.

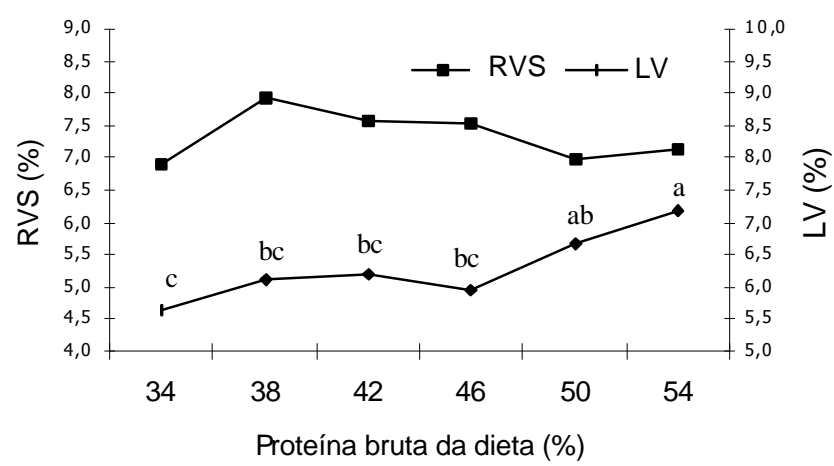

Figura 2 - Relação víscero-somática (RVS) e níveis de lipídio visceral (LV) (letras diferentes representam diferenças pelo Teste de Tukey $\mathrm{P}<0,05$ ).

\section{REFERÊNCIAS BIBLIOGRÁFICAS}

ANDERSON, R.J.; KIENHOLZ, E.W.; FLICKINGER, S.A. Protein requirements of smallmouth bass and largemouth bass. Journal of Fish Nutrition, v.111, p.1085-1097, 1981.

ASSOCIATION OF OFFICIAL ANALYTICAL CHEMISTS. Methods of analysis. 14. ed. Washington: AOAC, 1985. p.152-160.

BIDINOTO, P.M.; MORAES, G.; SOUZA, R.H.S Hepatic glycogen and glucose in eight tropical fresh water teleost fish: a procedure for field determinations of micro samples. Boletim Técnico do CEPTA, v.10, p.53-60, 1997.

BRECKA, B.J.; WAHL, D.H.; HOOE, M.L. Growth, survival and body composition of largemouth bass fed various commercial diets and protein concentrations. The Progressive Fish Culturist, v.58, p.104-110, 1996.

BROWN, M.L.; NEMATIPOUR, G.R.; GATLIN, D.M. Dietary protein requirement of juvenile sunshine bass at different salinities. The Progressive of Fish Culturist, v.54, p.148-156, 1992.

CHRISTIANSEN, C.; KLUNGSOYR, L. Metabolic utilization of nutrients and the effects of insulin in fish. Comparative Biochemistry Physiology, v.88b, p.701-711, 1987.

CONTRERAS G., E. A new approach to the evaluation of fishmeal quality by reaction with 2, 4, 6-trinitrobenzenesulfonic acid. In: CHANG, Y.K; WANG, S.S. Advances in extrusion technology. Lancaster: Technomic Publishing, 1999. p.179-189.

DIAS, J.; ALVAREZ, M.J.; DIEZ, A.; ARZEL J.; CORRAZE, G.; BAUTISTA, J.M.; KAUSHIK, S.J. Regulation of hepatic lipogenis by dietary protein/energy in juvenile European seabass (Dicentrarchus labrax). Aquaculture, v.161, p.169-186, 1998.

ERFANULLAH; JAFRI, A.K. Growth, feed conversion, body composition and nutrient retention efficiencies in fingerling catfish, Heteropneustes fossilis (Bloch), fed different sources of dietary carbohydrate. Aquaculture Research, v.30, p.43-49, 1999.

FOLCH, J.; LEES, M.; SLOANE-STANLEY, G.H. A simple method for the isolation and purification of total lipids from animal tissues. Journal of Biological Chemistry, v.226, p.497-509, 1957.

GALLAGHER, M.L. Apparent digestibility coefficients for some carbohydrates in diets for hybrid striped bass Morone saxatilis $x M$. chrysops. Journal of the World Aquaculture Society, v.28, n.4, 1997.

GARLING, D.M.; WILSON, R.P. Effects of dietary carbohydrateto-lipid ratios on growth and body composition of fingerling channel catfish. The Progressive Fish Culturist, v.39, p.43-47, 1977.

HANLEY, F. Effects of feeding supplementary diets containing varying levels of lipid on growth, food conversion, and body composition of Nile tilapia, Oreochromis niloticus (L.). Aquaculture, v.93, p.323-334, 1991.

HEIDINGER, R.C.; CRAWFORD S.D. Effect of temperature and feeding rate on the liver-somatic index of the largemouth bass, Micropterus salmoides. Journal of the Fisheries Research Board of Canada, v.34, p.633-638, 1977.

HEINEN, J.M. Light control for fish tanks. The Progressive Fish Culturist, v.60, p.323-330, 1998.

HILTON, J.W.; ATKINSON, J.L. Response of rainbow trout (Salmo gairdineri) to increased levels of available carbohydrate in practical trout diets. British Journal of Nutrition, v.47, p.597-607, 1982.

HUI-MENG, K. Aquatic feed pelleting techniques. In: PEOPLE'S REPUBLIC OF CHINA AQUACULTURE AND FEED WORKSHOP, Beijing, 1989. Proceedings. Beijing: American Soybean Association, 1989. p.237-244. 
HUNG, S.O.; FYNN AIKINS, F.K.; LUTES, P.B.; XU, R. Ability of juvenile white sturgeon (Acipenser transmontanus) to utilize different carbohydrate source. Journal of Nutrition, v.119 p.727-733, 1989.

JOBLING, M.; KOSKELA, J.; SAVOLAINEN, R. Influence of dietary fat level and increased adiposity on growth and fat deposition in rainbow trout, Oncorhynchus mykiss (Walbaum). Aquaculture Research, v.29, p.601-607, 1998.

KEARNS, J.P. Advantages of extrusion cooking and comparisons with the pelleting process for aquatic feeds. In: PEOPLE'S REPUBLIC OF CHINA AQUACULTURE AND FEED WORKSHOP, Beijing, 1989. Proceedings. Beijing: American Soybean Association, 1989. p. 245-269.

KEARNS, J.P. Ingredient consideration, preparation of feeds, selection of extrusion equipment and automatic controls for extrusion of pet and aquatic feeds. In: CHANG, Y.K; WANG, S.S. Advances in extrusion technology. Lancaster: Technomic Publishing, 1999. p.97-106.

LEE, D.J.; PUTMAN, G.B. The response of rainbow trout to varying protein/energy ratios in a test diet. Journal of Nutrition, v.103, p.916-922, 1973.

LOVSHIN, L.L.; RUSHING, J.H. Acceptance by largemouth bass fingerlings of pelleted feed with a gustatory additive. The Progressive Fish Culturist, v.51 p.73-78, 1989.

MILLIKIN, M.R. Effects of dietary protein concentration on growth, feed efficiency, and body composition of age- 0 striped bass. Transactions of the American Fisheries Society, v.111, p.373-378, 1982.

MINISTÉRIO DA AGRICULTURA E ABASTECIMENTO. Compêndio brasileiro de alimentação animal. Brasília: Departamento de Fiscalização e Fomento Animal - SDR/MA, 1998.

MOON, T.W.; FOSTER, W.; PLISETSKAYA, E.M. Changes in peptide hormones and lives enzymes in the rainbow trout deprived of food for 6 weeks. Canadian Journal of Zoology, v.67, p.2189-2193, 1989.

MOORE, B.J.; HUNG, S.S.O.; MEDRANO, J.F. Protein requirements of hatchery-produced juvenile white sturgeon (Acipenser transmontanus). Aquaculture, v.71, p.235-245, 1988.

MORAES, G.; OLIVEIRA, M.C.; RATIN, F.T. The metabolic pattern changes of Hoplias malabaricus from normoxia to hypoxia conditions. Revista Brasileira de Biologia, v.56, p.191-196, 1996.

MURAI, T. Protein nutrition of rainbow trout. Aquaculture, v.100, p.191-207, 1992.

NAGAI, M; IKEDA, S. Carbohidrate metabolism in fish. II Effect of dietary composition on metabolism of glucose $6{ }^{14} \mathrm{C}$ in carp. Bulletin of Japanise Society Science Fisheries, v.37, p.410-414, 1971.

NATIONAL RESEARCH COUNCIL. Nutrient requirements of fish. Washington: National Academy Press, 1993. 105p.

NEMATIPOUR, R.G.; BROWN, M.L.; GATLIN III, D.M. Effects of dietary energy: protein ratio on growth characteristics and body composition of hybrid striped bass, Morone chrysops $\mathrm{x}$ M. saxatilis. Aquaculture, v.107, p.359-368, 1992a.
NEMATIPOUR, R.G.; BROWN, M.L.; GATLIN III, D.M. Effects of dietary carbohydrate-to-lipid ratios on growth and body composition of hybrid striped bass. Journal of the World Aquaculture Society, v.23, p.128-132, 1992b.

PÉREZ, L.; GONZALES, H.; JOVER, M.; FERNÁNDEZ CARMONA, J. Growth of European sea bass fingerlings (Dicentrarchus labrax) fed extruded diets containing varying levels of protein, lipid and carbohydrate. Aquaculture, v.156, p.183-193, 1997.

PEZZATO, L.E. Alimentos convencionais e não-convencionais disponíveis para a indústria da nutrição de peixes e crustáceos. In: SIMPÓSIO INTERNACIONAL SOBRE NUTRIÇÃO DE PEIXES E CRUSTÁCEOS, 1., Campos do Jordão, 1995. Anais. Campinas: CBNA, 1995. p.34-52.

PEZZATO, L.E. O estabelecimento das exigências nutricionais das espécies de peixes cultivadas. In: SIMPÓSIO SOBRE MANEJO E NUTRIÇÃO DE PEIXES, 1., Piracicaba, 1997. Anais. Piracicaba: CBNA, 1997. p.45-62.

REFSTIE, T.; AUSTRENG, E. Carbohydrate in rainbow trout diets: III. Growth and chemical composition of fish from different families fed four levels of carbohydrate in the diet. Aquaculture, v.25, p.35-49, 1981.

SAS Institute. SAS user's guide: statistics. 5.ed. Cary: Statistical Analysis System Institute, 1985.

SHEARER, K.D. Factors affecting the proximate composition of cultured fishes with emphasis on salmonids. Aquaculture, v.119, p.63-88, 1994.

SOENGAS, J.L.; ALBEGUNDE, M.; ANDRÉS, M.D. Gradual transfer to sea water of rainbow trout: Effects on liver carbohydrate metabolism. Journal of Fish Biology, v.47, p.466-478, 1995.

STEFFENS, W. Principles of fish nutrition. Chichester: Ellis Harwood, 1989. p.184-208.

STRYER, L. Metabolismo do glicogênio. In: STRYER, L. Bioquímica. Rio de Janeiro: Guanabara, 1971. cap.19, p.371-386.

SULLIVAN, J.A; REIGH, R.C. Apparent digestibility of selected feedstuffs in diets for hybrid striped bass (Morone saxatilis $\mathrm{x}$ Morone chrysops). Aquaculture, v.138, p.313-322, 1995.

TAKEUCHI, T. Laboratory work - chemical evaluations of dietary nutrients. In: WATANABE, T. Fish nutrition and mariculture. Tokyo: Aquatic Biosciences, 1988. cap.3, p.179-233.

TIDWELL, J.H.; WEBSTER, C.D.; COYLE, S.D. Effects of dietary protein level on second year growth and water quality for largemouth bass (Micropterus salmoides) raised in ponds. Aquaculture, v.145, p.213-223, 1996.

WICKER, A.M.; JOHNSON, W.E. Relationships among fat content, condition factor, and first year survival of Florida largemouth bass. Transactions of the American Fisheries Society, v.116, p.264-271, 1987.

Recebido em 22.11.99 